DOI: https://doi.org/10.24867/12DS04Stojanovic

\title{
VREDNOVANJE PREDLOGA REŠENJA ZA POBOLJŠANJE USLOVA ODVIJANJA SAOBRAĆAJA NA RASKRSNICI LESKOVCU
}

\section{EVALUATION OF THE PROPOSED SOLUTION FOR IMPROVING THE CONDITIONS OF TRAFFIC AT THE INTERSECTION IN LESKOVAC}

\begin{abstract}
Stefan Stojanović, Nenad Ruškić,
Oblast - SAOBRAĆAJ I TRANSPORT

Kratak sadržaj - U okviru rada izvršena je analiza uslova odvijanja saobraćaja na postojećoj raskrsnici sa aspekta nivoa usluge. Date je predlog mera za poboljšanje uslova odvijanja saobraćaja po varijantama, vrednovani su dobijeni rezultati, i predloženo je najbolje rešenje.

Ključne reči: Nivo usluge, vrednovanje

Abstract - The paper analyzes the traffic flow conditions at the existing intersection from the aspect of service level. A proposal was made for measures to improve traffic conditions by variants, the results obtained were evaluated, and the best solution was proposed.
\end{abstract}

Keywords: Service level, evaluation

\section{UVOD}

Saobraćaj je organizovano kretanje vozila definisanim saobraćajnicama. Saobraćaj se organizuje na osnovu normativnog uređenja (propisi o bezbednosti saobraćaja), pravilima saobraćaja (koja određuju način kretanja i međusobne odnose u saobraćaju) i građevinskim merama (izgrađenost saobraćajnica i okoline puta) i tehničkim regulisanjem (saobraćajnom signalizacijom i opremom puta).

Saobraćajni problemi u gradu su obično vezani za kapacitivne sposobnosti delova mreže. Stanje i mogućnost gradske putne mreže uslovljavaju funkcionalnost gradskih sistema koji koriste zajedničke površine.

Da bi se ostvarili poželjni uslovi odvijanja saobraćaja i smanjile konfliktne situacije moraju se primenjivati određene rekonstruktivne, regulativne $\mathrm{i}$ restriktivne mere. Gradska putna mreža je pod velikim pritiskom masovnosti individualnog motornog prevoza.

Jedna od regulativnih mera je regulisanje saobraćaja svetlosnom signalizacijom. Ovom merom se može postići poboljšanje odvijanja uslova saobraćaja na mestima sukobljavanja konfliktnih tokova.

Raskrsnice su čvorišta u kojima se vrši ukrštanje saobraćajnica istog ili različitog ranga.

Najbrojniju grupu raskrsnica u gradu čine površinske raskrsnice kod kojih se interni odnosi učesnika u saobraćaju rešavaju na zajedničkoj kolovoznoj površini.

\section{NAPOMENA:}

Ovaj rad proistekao je iz master rada čiji mentor je bio dr Nenad Ruškić, vanr. prof.
Površinske raskrsnice mogu biti razvrstane u tri podele: nesignalisane, kružne, signalisane. Prema obliku površinske raskrsnice delimo na: četvorokrake, trokrake, kružne i višekrake.

Prema geometriji mogu biti nesimetrične, standardne i nestandardne raskrsnice. Denivelisane raskrsnice se koriste na ukrštanjima puteva istog ili različitog ranga, gde je zbog ranga povezivanje puteva u mreži ili zbog veličine saobraćajnih tokova nemoguće izvesti površinske raskrsnice.

Površinske raskrsnice su mnogo prisutnije u praksi kako zbog potreba tako i zbog finansiranja.

Predmet rada jeste vrednovanje predloga rašenja za poboljšanje uslova odvijanja saobraćaja na raskrsnici Bulevara Nikole Pašića i Ulica Dimitrije Tucovića koja se nalazi u Leskovcu. Raskrsnica je četvorokraka standardna nesignalisana.

Nakon uvodnog dela, u okviru rada, izvršena je analiza postojećeg stanja uslova odvijanja saobraćaja na raskrsnici, zatim su opisani uslovi odvijanja saobraćaja na nesignalisanim raskrsnicama i osnovni pojmovi o signalisanim raskrsnicama, kružnim raskrsnicama, proračun kapaciteta i nivoa usluge, kao i predlog rešenja problema.

Funkcionalnim, ekološkim i ekonomskim vrednovanjem predloženih rešenja dobijeno je optimalno rešenje koje je i predloženo za realizaciju.

\section{KARAKTERISTIKE ANALIZIRANE RASKRSNICE}

Analizirana raskrsnica nalazi se na području grada Leskovca. Locirana je u industrijskoj zoni i mesto je ukrštanja Bulevara Nikole Pašića i Ulice Dimitrija Tucovića, sl. 1.

\section{PROGNOZA SAOBRAĆAJNOG RASTA}

Saobraćajno opterećenje i nivo usluge od značajnog su uticaja za dimenzionisanje poprečnog profila, dok su merodavne brzine i merodavna vozila od uticaja na elemente projektne geometrije. Saobraćajno opterećenje predstavlja broj vozila i/ili pešaka koja u određenom vremenskom intervalu prolaze ili se očekuje da će proći kroz određeni putni presek. Dodatni faktori koji utiču na saobraćajno opterećenje predstavljeni su karakteristikama puta:

\footnotetext{
- brojem saobraćajnih traka,

- širinom saobraćajnih traka,

- podužnim nagibom nivelete kolovoza,

- dinamičkim uticajima.
} 


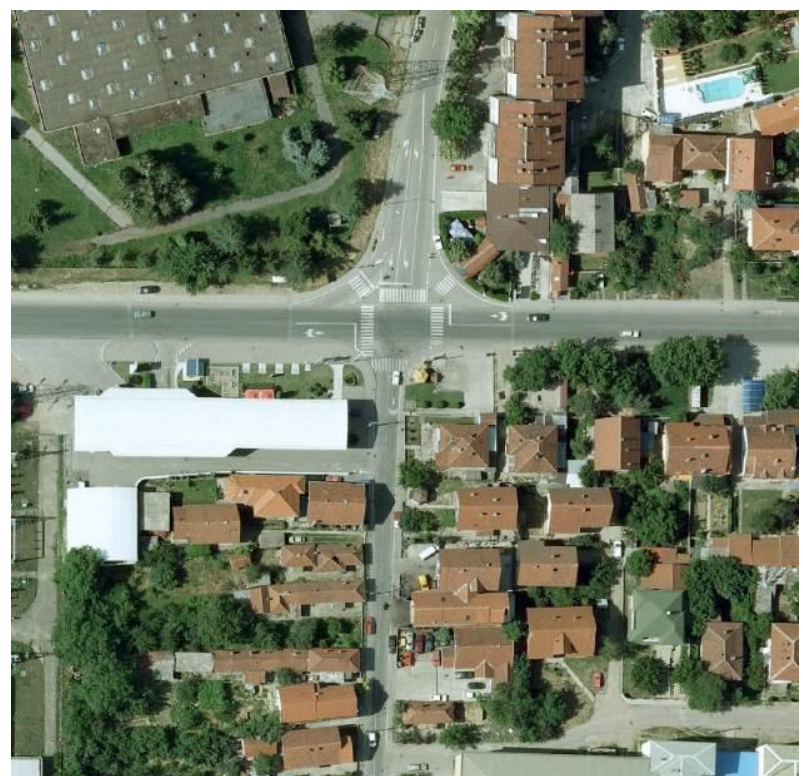

Slika 1. Položaj analizirane raskrnice na uličnoj mreži grada Lekovca.

Razlikujemo postojeće i planirano stanje.

Postojeće saobraćajno opterećenje (može se prebrojati) i koristi se za preduzimanje neposrednih akcija u regulisanju saobraćaja.

Tabela 1. Broj vozila u vršnom času po prilazu

\begin{tabular}{|l|c|}
\hline Godine & 2020 Bazna godina \\
\hline Voz/h ( u vršnom periodu) & 1174 \\
\hline Prilaz 1 & 212 \\
\hline Prilaz 2 & 444 \\
\hline Prilaz 3 & 82 \\
\hline Prilaz 4 & 436 \\
\hline
\end{tabular}

\subsection{Prognozirano saobraćajno opterećenje}

Prognozirano saobraćajno opterećenje daje buduće količine saobraćaja za koje treba obezbediti odgovarajuće kapacitete gradske putne mreže i sistema javnog gradskog prevoza.

Opšti obrazac za prognozu saobraćaja glasi:

$$
\begin{gathered}
\mathrm{V}_{\mathrm{i}}^{\mathrm{n}}=\mathrm{V}_{\mathrm{i}}^{\mathrm{BAZ} * \mathrm{~F}_{\mathrm{i}}^{\mathrm{n}}} \\
F_{i}^{n}=\left(\mathrm{I}+\mathrm{e}^{*} R_{B D P}^{n} \%\right)
\end{gathered}
$$

Gde je:

$\mathbf{V}_{\mathbf{i}}^{\mathbf{n}}$ - saobraćajni tok za vozila (i) u godini (n) dobijen prognozom saobraćaja;

$\mathbf{V}_{\mathbf{i}}^{\mathbf{B A Z}}$ - utvrđeni saobraćajni tok za vozila (i) u baznoj godini dobijen na terenu;

$\mathbf{F}_{\mathbf{i}}^{\mathbf{n}}$ - faktor rasta saobraćajnog toka za vozila (i) u periodu tj. godini (n);

$\boldsymbol{R}_{\boldsymbol{B D P}}^{\boldsymbol{n}} \%$ - prosečna godišnja stopa rata BDP-a u periodu, tj. do n-te godine;

$\mathrm{N}$ - broj godina po periodima.

Razvoj oblasti vezane za prognozu saobraćaja desio se u okolnostima kada je porast saobraćaja izazvan brzim razvojem i masovnom upotrebom putničkih automobila, pre svega u gradovima, počeo da stvara brojne probleme, pa se pojavila potreba za složenijim oblicima praćenja, analize i kontrole razvoja saobraćaja. Polovinom prošlog veka došlo je do intenzivnog razvoja računarske tehnologije i njene prime u prognozi saobraćaja.

Prognoza saobraćaja je veoma važna prilikom odabira buduće varijante nekog projekta. Ukoliko se predviđanje saobraćaja ne obavi na pravi način izgrađeni saobraćajni objekat neće moći da zadovolji potrebe za zahtevanim kapacitetom ili će biti predimenzionisan. Usled ovoga javlja se veliki problem koji se mora opet rešavati i njegovi troškovi proširenja ili ponovne izgradnje mogu da koštaju više nego što je stajala sama izgradnja prvobitnog objekta.

\section{PREDLOG REŠENJA}

Razvoj i testiranje varijantnih rešenja predstavlja jednu od ključnih faza u ovom radu. Cilj ovog rada jeste da se na osnovu postojećih geometrijskih ograničenja predlože i analiziraju varijante, kako bi se našlo optimalno rešenje za datu raskrsnicu. Analizom rezultata kapaciteta i nivoa usluge za posmatranu raskrsnicu utvrđeno je da sadašnja organizacija i odvijanje saobraćaja ne mogu da zadovolje nesmetano kretanje saobraćaja. Potrebno je izvesti najbolju i najoptimalniju varijantu kako bi se prevazišao problem i poboljšao nivo uslugena svim prilazima na raskrsnici. Predložene varijante su:

1. Varijanta 1 - Četvorokraka nesignalisana raskrsnica -

Zadržava se postojeća geometrija raskrsnice, sa manjim izmenama.

2. Varijanta 2 - Četvorokraka signalisana raskrsnica

3. Varijanta 3 - Kružna raskrsnica sa jednom trakom u kruženju - Menja se geometrija raskrsnice. Umesto postojeće četvorokrake, projektuje se kružna raskrsnica. Postavlja se nova vertikalna i horizontalna signalizacija.

$\mathrm{Na}$ osnovu predloženih varijanti odlučivaće se koja je varijanta najpovoljnija za posmatranu raskrsnicu, ali treba voditi računa da izabrana varijanta pruža bolje uslove odvijanja saobraćaja, da smanji ili eliminiše zastoje i formiranje redova, da se smanje vremenski gubici i da se poboljša nivo usluge na celoj raskrsnici.

\section{TROŠKOVI GRADNJE}

Vrednovanje projekata predstavlja proceduru ocenjivanja i odlučivanja u sistemu osmišljavanja optimalnog razvoja i korišćenja putne mreže i putnih objekata. Vrednovanje projekata je veoma važno i koristi se u slučajevima kada se razmatra više varijanti. Može se sprovoditi u različitim fazama projekata. Postupak vrednovanja najčešće je vezan za prethodnu studiju izvodljivosti i studiju izvodljivosti koje su sastavni deo generalnog projekta.

Vrednovanje projekata pri izgradnji raskrsnice ima za cilj da omogući analizu više alternativa, te da se na osnovu ekonomske opravdanosti, i sa bezbednosnog i ekološkog aspekta, odabere najbolja varijanta [1].

\subsection{Nesignalisana četvorokraka raskrsnica}

Zadržava se postojeća geometrija raskrsnice, stim da je potrebno zastarelu saobraćajnu signaizaciju zameniti sa novom odgovarajućom, takođe i oznake na kolovozu je potrebno ponovo obeležiti o mogućstvu sa hladnom plastikom. 


\subsection{Signalisana četvorokraka raskrsnica}

Zadržava se postojeća geometrija raskrsnice sa dodavanjem trake na istočnom i zapadnom prilazu, sa uvođenjem odgovarajuće svetlosne segnalizacije prema situaciji sa slike isopod. Takođe potrebno je raskrsnicu obeležiti odgovarajućom vertikanom i horizontalnom signalizacijom prema novoj situaciji.

\subsection{Kružna raskrsnica}

Kružna raskrsnica sa jednom trakom u kruženju - Menja se potpuna geometrija raskrsnice. Projektovana kružna raskrsnica je sa jednom trakom u kruženju i sa po jednom trakom na ulivnom/izlivnom grlu. Potrebno je elemente horizontalne i vertikalne signlizcije prilagoditi novoj situaciji. Projektovana kružna raskrsnica je sa centralim trgom koji je planiran da bude zelena površina odgovarajuće oivičen i sa prelaznim krugom radi lakšeg kretanja teretnog vozila.

\section{6. ŠIRI UTICAJ SAOBRAĆAJA NA DRUŠTVO I ŽIVOTNU SREDINU}

U ukupnom zagađivanju atmosfere saobraćaj učestvuje sa oko $50 \%$ i jedan je od najvećih zagađivača. Sagorevanjem goriva dolazi do emisjije niza štetnih polutanata ( ugljen dioksid $\mathrm{CO} 2$, ugljen monoksid $\mathrm{CO}$,ugljovodonici $\mathrm{CxHy}$, azotni oksidi NOx, sumpor dioksid SO2, čvrste čestice prašina, čađ, dim i teški meali kao što je olovo i dr.), u atmosferu u količinama koje se prirodnim putem ne mogu razgraditi (Slika 2). Konstantni porast obima saobraćaja, pored ekonomskog prosperiteta ima i za direktnu posledicu da je zagađivanje vazduha sagorevanjem goriva $u$ motornim vozilima postao jedan od najvećih problema naselja i gradova. Uticaj saobraćaja na zagađenje vazduha može se ispoljiti u neposrednoj blizini samog izvora zagađenja, ali na regionalnom i globalnom nivou.

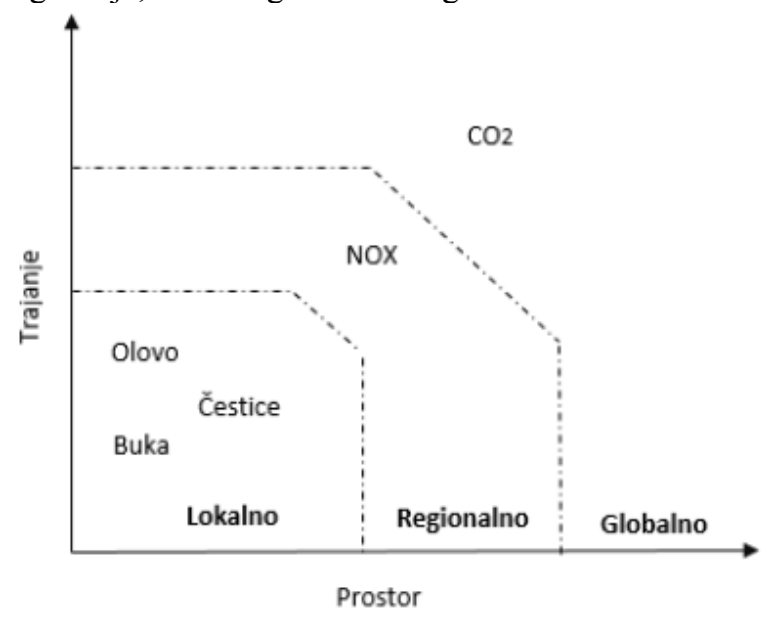

Slika 2. Prostorni i vremenski uticaj pojedinih zagađujućih materija

Troškovi zagađenja vazduha u saobraćaju prouzrokovani emisijom zagađivača vazduha, obuhvataju 4 osnovne grupe troškova:

1. Zdravstvene troškove;

2. Gubitke na usevima u poljoprivredi i druge gubitke $u$ vezi sa biosferom:

3. Štete nastale na zgradama i materijalima i

4. Posledice na biodiverzitet i ekosistem (zemlju,vodu/podzemne vode).

\subsection{Buka}

Svaki neželjeni zvuk je buka. Svaka zvučna pojava koja ometa rad ili odmor predstavlja buku. U praksi, zvuk je različite jačine, zavisno od uslova i okolnosti u kojima se javlja i deluje. U zemljama EU 40\% stanovništva izloženo je $24 \mathrm{~h}$ ekvivalentnom nivou buke većem od $55 \mathrm{~dB}$ (A) kao posledice drumskog saobraćaja, dok je $20 \%$ stanovništva izloženo ekvivalentnom nivou buke koji prelazi $65 \mathrm{~dB}$ (A) što ozbiljno ugrožava san i dovodi do pojave psihosomatskih simptoma akustičnog stresa.

Postoji nekoliko načina da se efekti buke iskažu novčano u transportnim projektima. Jedan metod je da se koriste tkv. „objavljene reference“ (tržišne vrednosti nekretnina ili zdravstveni troškovi). Postoji literatura o efektu dodatne buke na (smanjenje) vrednosti kuća. Imajući u vidu broj kuća pogođenih bukom zbog projekta i prosečne cene kuće mogu se izračunati ukupni troškovi. U drugim metodama koriste se iritacija i zdravlje kao i spremnost da se prihvati kompenzacija ili spremnost da se plati za smanjenje buke. Troškovi buke variraju u odnosu na doba dana, gustinu naseljenosti i blizinu izvora buke i nivo postojeće buke. U projektima drumskog transporta ova vrednost zavisi od brzine vozila, učešća teretnih vozila, stanja, nagiba puta, i načina vožnje.

\subsection{Troškovi klimatskih promena}

Trenutno ne postoji koncenzus o tome da li i kako klimatske promene $\mathrm{i}$ efekat staklene bašte treba uvrstiti $\mathrm{u}$ analizu troškova i koristi. Većina razvijenih zemalja koje uvršćuju efekat staklene bašte koristi novčano vrednovanje emitovanje emisije CO2. Za Srbiju ne postoje vrednosti konkretno vezane za klimatske promene.

\subsection{Troškovi zagušenja (zastoj)}

Za razliku od vrednovanja podloga rešenja i troškova gradnje kojima je dat primarni cilj ovog rada, analizi potrošnje goriva i zagađenja vazduha je data sekundarna uloga. Razlog zbog kojeg je to učinjeno nalazi se $u$ samom zadatku ovoga rada, a to je prevenstveno mogućnost poboljšasanja uslova odvijanja saobraćaja $u$ baznoj i prognoziranoj godini. Međutim, skladno zadatku ovoga rada rešavaće se i problem potrošnje goriva i zagađenja vazduha. Kako se bude tražilo rešenje koje će ponuditi najbolje uslove za odvijanje trenutnog i prognoziranog saobraćaja, potrošnja goriva i zagađenje vazduha će se svesti na najmanju moguću meru. Vremenski gubici koji se javljaju na raskrsnici u direktnoj su vezi sa potrošnjom goriva i zagađenjem vazduha. Usled većih vremenskih gubitaka na raskrsnici raste potrošnja goriva, a samim tim i zagađenje vazduha. Ako su uslovi odvijanja saobraćaja opisanim višim nivoima usluge potrošnja goriva je niža kao i zagađenje vazduha.

Troškovi potrošnje goriva i zagađenja vazduha na najbolji način opisuju uslove odvijanja saobraćaja u pojedinim predlozima rešenja. Preko troškova potrošnje goriva i zagađenja vazduha na najbolji mogući način (novčano) se mogu opisati problemi vremenskih gubitaka u saobraćaju. Kada se pronađe optimalno rešenje za uslove odvijanja saobraćaja, direktno će se uticati na smanjenje potrošnje goriva i poboljšanja životne sredine. Jedini način na koji se može uticati na smanjenje zagađenja vazduha pored izbora optimalnog rešenja regulisanja saobraćaja je i da se 
zakonskim merama utiče na kvalitet proizvodnje pogonskog goriva kao i zabranom učestvovanja vozilima u saobraćaju čiji pogonski agregati ne ispunjavanju visoke standarde u pogledu ispuštanja izduvnih gasova.

\section{ZAKLJUČAK}

Analiza koja je urađena u ovom radu treba da da odgovor da li je postojeće stanje fukcionalno i da li postoji bolje rešenje. Nakon obavljene analize postojećeg stanja preložena su 3 predloga za rešavanje postojećeg stanja. Pored uslova odvijanja saobraćaja urađeni su i troškovi gradnje s ciljem da se pronađe rešenje koje bi bilo izvodljivo i u skladu sa ekonomskim mogućnostima. Da bi se na najbolji mogući način opisali uslovi odvijanja saobraćaja u pojedinim varijantama urađena je analiza potrošnje goriva i zagađenja vazduha da bi se vremenski gubitci mogli iskazati novčano.

U okviru rada određeni su pored uslova odvijanja saobraćaja i troškovi gradnje varijantnih rešenja, kako bi se pronašlo rešenje koje je optimalno i koje će doprineti poboljšanju celokupnog nivoa usluge raskrsnice. Uslovi odvijanja saobraćaja trenutno nisu zadovoljavajući jer na Prilazu 2 i Prilazu 4 za leva skretanja trenutno je u vršnom periodu nivo usluge $\mathrm{D}$ odnosno $\mathrm{F}$.

Na osnovu analize ukupnih troškova može se zaključiti da troškovi Varijante $1 \mathrm{u}$ trenutnom stanju iznose 14.242 eura, prognoziranom 28.435 eura i troškovi Varijante $3 \mathrm{u}$ trenutnom stanju iznose 13.402 eura i prognoziranom 169.196 eura ove dve varijante daju najbolje, rezultate u pogledu potrošnje goriva, što znači da Varijanta 2 neće uzimati u obzir kao rešenja za dati problem. Treba napomenuti da ćemo u Vaijanti 2 imati i troškove održavanja rada svetlosne signalizacije. Ovi troškovi nisu razmatrani u radu ali i oni predstavljaju dodatnu stavku troškova.
Ukupni troškovi Varijante 1 zanemarljivo su manji od troškova Varijante 3, s obzirom na to da je nivo usluge $\mathrm{u}$ Varijanti 3 i u postojećem i u prognoziranom stanju znatno bolji od Varijante 1.

$\mathrm{Na}$ osnovu dobijenih rezultata može se zaključiti da je optimalno i najracionalnije usvojiti Varijantu 3. Tj, rekonstrukciju postojeće četvorokrake raskrsnice i gradnju kružne raskrsnice.

\section{LITERATURA}

[1] Mitić, D., dr Vukanović S., Kružne raskrsnice, Saobraćajni fakultet, Beograd 1994.

[2] Pravilnik o saobraćajnoj signalizaciji (,Službeni glasnik RS", broj 85/17)

\section{Kratka biografija:}

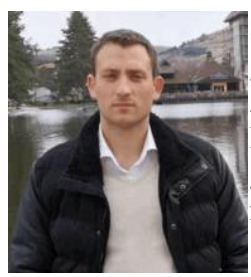

Stefan Stojanović rođen u Leskovcu 1994. godine, Visoku Tehničku školu u Nišu zavrsio 2016. godine, osnovne studije na Fakultetu tehniičkih nauka završio 2018. godine, iste godine upisuje master studije na Fakultetu tehničkih nauka.

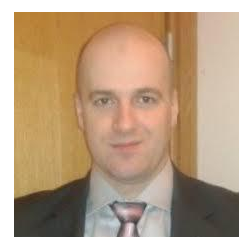

Nenad Ruškić rođen je u Tuzli 1980. Doktorirao je na Fakultetu tehničkih nauka 2013. godine 